\title{
Studies on the Oxidation and Peroxide Scavenging Potentials of Tissues in Spontaneously Hypertensive Rats (SHR) and Stroke-Prone SHR
}

\author{
Isao Tomita, Mitsuaki Sano, Shigeo Serizawa, \\ Tomoko Takata, and Masako Furukawa
}

Lipid peroxides are highly toxic and are assumed to be closely correlated to the age-related biochemical changes in tissues, especially to the susceptibility of cell membranes.

In the present study, the formation of lipid peroxides and peroxide scavenging systems in SHR and stroke-prone SHR (SHRSP) fed on CMF diet (protein 30.4\%, lipid $8.3 \%$, carbohydrate $44.0 \%$, cellulose $3.7 \%$, ash $6.6 \%$, water $7.0 \%$, dl- $\alpha$-tocopherol $20 \mathrm{mg} 372.3 \mathrm{Cal} / 100 \mathrm{Gm}$ ) was investigated. The studies on SHR and SHRSP fed on the synthetic diet (protein $22.9 \%$, lipid $6.0 \%$, carbohydrate $46.5 \%$, cellulose $9.5 \%$, ash $6.3 \%$, water $8.5 \% 332 \mathrm{Cal} / 100 \mathrm{Gm}$ ) with or without $20 \mathrm{mg}$ of dl- $\alpha$-tocopheryl acetate were also carried out.

Lipid peroxides in tissue homogenates were determined by thiobarbituric acid method (TBA) according to Masugi et al (Seikagaku 48: 420, 1976). Total and protein bound sulfhydryl contents were analyzed with DTNB. DPPH was used for the determination of free radical producing substances. The activity of superoxide dismutase (SOD) was determined with $101,000 \times \mathrm{g}$ supernatant of tissues after dialysis for 10 hours according to Elstner et al (Anal Biochem 70: 616, 1976). Glutathione peroxidase $\left(\mathrm{GSH}_{\mathrm{PX}}\right)$ activity was determined by DTNB method in the presence of $\mathrm{H}_{2} \mathrm{O}_{2}$ (Hafeman et al: J Nutr 104: 580, 1974).

Lipid peroxides determined as TBA reactant (malon dialdehyde) were $1.12 \pm$ 0.05 (mean $\pm \mathrm{SE}, 2$ months) and $1.41 \pm 0.09$ (7 months) $\mathrm{n}$ moles $/ \mathrm{mg}$ protein in the brains of SHRSP while they were $1.12 \pm 0.12$ (2 months) and $1.27 \pm 0.11$ ( 7 months) in those of SHR. The lipid peroxide level in 7-month-old SHRSP was significantly elevated $(\mathrm{p}<0.02)$. The changes of the values in livers of SHRSP and SHR were not significant. The activities of $\mathrm{GSH}_{\mathrm{Px}}$ in the brains of SHRSP were $1.31 \pm 0.41$ (2 months), $3.29 \pm 0.51$ (5.5 months), and $3.10 \pm 0.32$ ( 7 months) unit/mg protein. The latter 2 values of 5.5 and 7 months were significantly higher than that of 2 months ( $\mathrm{p}<0.02,0.01$ respectively), while no significant change was observed in the brains of 2 and 7 -month-old SHR. It must also be noted that liver $\mathrm{GSH}_{\mathrm{PX}}$ activity increased largely with age in SHRSP but not in SHR. Significant increases of DPPH reactive substances and protein bound $\mathrm{SH}$ were observed in the brains of 7-month-old SHRSP while no remarkable change was obtained in both liver and brain of SHRSP and SHR.

SHRSP which received synthetic diet with dl- $\alpha$-tocopherol for 6 months showed the marked decrease of peroxide formation in both liver and brain as compared with SHRSP fed on the diet without tocopherol. 
Blood pressure, GSH $\mathrm{FX}_{\mathrm{PX}}$, SOD, and T-SH in livers and brains of SHRSP were all very slightly lowered by the tocopherol supplementation.

Large effect of CMF diet on $\mathrm{GSH}_{\mathrm{PX}}$ in liver of SHRSP is under careful investigation.

This study was supported by the Science and Technology Agency of Japanese Government. 